\title{
ROBÓTICA NA EDUCAÇÃO: Uma Revisão da Literatura
}

\author{
ROBOTICS IN EDUCATION: A Literature Review \\ LA ROBÓTICA EN LA EDUCACIÓN: una revisión de literatura
}

\author{
Ulisses Queiroz Parreira* (D) \\ Deive Barbosa Alves** (iD) 9 \\ Marcos Antonio de Sousa ${ }^{* * *}$ (D) 9
}

\begin{abstract}
RESUMO
Esse artigo objetiva expor uma revisão bibliográfica pautada em teses e dissertações acadêmicas que fazem alusão à robótica na educação, defendidas no período compreendido entre fevereiro de $2016 \mathrm{e}$ março de 2021, em duas importantes bases, sendo elas: a Biblioteca Digital Brasileira de Teses e Dissertações (BDTD) e o Catálogo de Teses e Dissertações da CAPES (CTD). Com esta investigação, se pretendeu encontrar além dos avanços em tal temática, a maneira como a robótica vem sendo utilizada no contexto educacional. Para a viabilidade desta revisão, se fez uso de questões norteadoras, além de critérios de inclusão e exclusão para a seleção dos manuscritos. Como repercussão desta pesquisa, percebe-se uma quantidade discreta de investigações relacionadas a robótica em sala de aula, o acúmulo destas pesquisas, como apontado em análises anteriores, ainda permanece nas regiões Nordeste, Sul e Sudeste do Brasil. Apesar de abordagens distintas, nota-se que tais pesquisas sempre mencionam esta temática como estratégia, ferramenta, ou mesmo algo a ser inserido entre diferentes componentes curriculares, sempre visando o aprimoramento no processo de ensino-aprendizagem. Além disso, identificamos ainda que a mesma é tida como potencializadora do trabalho coletivo, permitindo que os estudantes programem, discutam e consequentemente, aprendam brincando.
\end{abstract}

Palavras-chave: Robótica Educacional. Educação. Revisão de Literatura.

\begin{abstract}
This article aims to present a bibliographical review based on academic theses and dissertations that allude to robotics in education, defended in the period between February 2016 and March 2021, in two important bases, namely: the Brazilian Digital Library of Theses and Dissertations (BDTD) and the CAPES Theses and Dissertations Catalog (CDT). With this investigation, it was intended to find, in

\footnotetext{
* Mestrando do Programa de Pós-Graduação em Ensino de Ciências e Matemática (PPGecim) da Universidade Federal do Tocantins (UFT). Professor de Matemática da Escola SESI de Araguaína/TO, Brasil. Rua da Prata, Qd. K6, Lt. 07, Setor Araguaína Sul, Araguaína/TO, Brasil, CEP 77.827-310. E-mail: uliqp@ mail.uft.edu.br *** Doutor em Educação e Ciências em Matemática pela Universidade Federal de Uberlândia (UFU). Professor do curso de Licenciatura em Matemática da Universidade Federal do Tocantins (UFT), Campus de Araguaína/TO. Professor do Programa de Pós-Graduação em Ensino de Ciências e Matemática (PPGecim) da Universidade Federal do Tocantins (UFT), Campus de Araguaína/TO, Brasil. Rua L, nº 272 Apto. 303, Setor Couto Magalhães, Araguaína/TO, Brasil, CEP 77.824-740. E-mail: deive@uft.edu.br

**** Mestrando do Programa de Pós-Graduação em Ensino de Ciências e Matemática (PPGecim) da Universidade Federal do Tocantins (UFT). Técnico Administrativo na Universidade Federal do Tocantins (UFT), Campus de Araguaína/TO, Brasil. Rua 15 Qd. 19 Lt. 02, Conjunto Residencial Patrocínio, Araguaína/TO, Brasil, CEP 77.826618. E-mail: marcos.sousa@uft.edu.br
} 
addition to advances in this theme, the way in which robotics has been used in the educational context. For the feasibility of this review, guiding questions were used, in addition to inclusion and exclusion criteria for the selection of manuscripts. As an impact of this research, there is a discreet amount of investigations related to robotics in the classroom, the accumulation of these researches, as pointed out in previous analyses, still remains in the Northeast, South and Southeast regions of Brazil. Despite different approaches, it is noted that such researches always mention this theme as a strategy, tool, or even something to be inserted between different curricular components, always aiming to improve the teaching-learning process. In addition, we also identified that it is seen as an enhancer of collective work, allowing students to program, discuss and, consequently, learn by playing.

Keywords: Educational Robotics; Education; Literature review.

\section{RESUMEN}

Este artículo tiene como objetivo exponer una revisión bibliográfica basada en las tesis y disertaciones académicas que aluden a la robótica en la educación, defendidas en el período comprendido entre febrero de 2016 y marzo de 2021, en dos importantes bases de datos, a saber: la Biblioteca Digital Brasileña de Tesis y Disertaciones (BDTD) y el Catálogo de Tesis y Disertaciones de CAPES (CDT). Con esta investigación, se pretendía encontrar además de los avances en dicho tema, la forma en que se ha utilizado la robótica en el contexto educativo. Para la viabilidad de esta revisión, se hizo uso de preguntas guía, además de criterios de inclusión y exclusión para la selección de los manuscritos. Como repercusión de esta investigación, se puede percibir una cantidad discreta de investigaciones relacionadas con la robótica en el aula, la acumulación de estas investigaciones, como se señala en las revisiones anteriores, todavía permanece en las regiones del Nordeste, Sur y Sudeste de Brasil. A pesar de los diferentes enfoques, se observa que dichas investigaciones siempre mencionan esta temática como estrategia, herramienta o incluso como algo a insertar entre los diferentes componentes curriculares, siempre con el objetivo de mejorar el proceso de enseñanza-aprendizaje. Además, también identificamos que se considera como un potenciador del trabajo colectivo, permitiendo a los alumnos programar, discutir y, en consecuencia, aprender jugando.

Palabras clave: Robótica educativa. La educación. Revisión de literatura.

\section{INTRODUÇÃO}

Ao observarmos as atividades desenvolvidas no contexto educacional nos últimos anos, percebe-se que aquelas em que o progresso do aluno resulta do seu esforço em assimilar (memorizando e copiando) o máximo de informações repassadas pelo professor, tem perdido espaço. Entende-se que os alunos não são mais os mesmos, e isso acaba impossibilitando o uso de abordagens estáticas em alunos, que impulsionados pela própria tecnologia, estão cada vez mais em movimento (PARREIRA; ALVES, 2021).

Acerca desta questão, Papert (1994) afirma que o referido atraso da escola se deu, visto que o ato de aprender ficou esquecido, enquanto o mundo acadêmico dedicou-se ao ato de ensinar: 
Por que não há, em inglês, uma palavra para a arte de aprender? O Webster diz que a palavra pedagogia significa a arte de ensinar. O que está faltando é uma palavra para a arte de aprender. [...] A Pedagogia, a arte de ensinar, sob seus vários nomes, foi adotada pelo mundo acadêmico como uma área respeitável e importante. A arte de aprender é um órfão acadêmico (PAPERT, 1994, p. 77).

A referida observação impulsionou o autor na busca de entendimentos das diversas formas de aprendizagem, dentre as diversas maneiras citadas por Papert (1994), está a Robótica. Tal temática, como a muito defendida por Papert, apresenta-se na visão de Barbosa (2016) como um modelo inovador no contexto educacional, pois, apesar de alguns percalços, vem se destacando nos mais variados níveis de ensino, resultando na produção de protótipos robóticos voltados para o ambiente escolar que acarretam em grande contribuição para o processo de construção do conhecimento. Remetemo-nos, assim, à Cesar (2009, p. 25) quando diz que:

Os projetos de Robótica [...] possibilitam, ainda, o rompimento com a perspectiva fragmentada e compartimentalizada do currículo escolar, ao trazer para a discussão temas que transversalizam diferentes áreas do conhecimento; requerem a colaboração entre os sujeitos envolvidos nos projetos e possibilitam a construção e experimentação de modelos.

Instigados por tais constatações, este artigo surge com o intuito de evidenciar, além dos avanços em tal temática, a maneira como a robótica vem sendo utilizada no contexto educacional ao longo dos últimos cinco anos. Como base de dados, teremos a Biblioteca Digital Brasileira de Teses e Dissertações (BDTD), e o Catálogo de Teses e Dissertações da CAPES (CTD).

Antes de adentrarmos ainda mais neste tema, uma análise se faz necessária pois, percebemos na literatura que propostas pedagógicas fundamentadas na robótica acabam sendo denominadas, ao menos, de três formas distintas entre os educadores, sendo elas: "Robótica Educativa e/ou Robótica Pedagógica ou Educacional. Antes de adotar uma das expressões, consideramos relevante diferenciar os termos educativo e pedagógico ou educacional" (CÉSAR 2013, p. 54).

Segundo o ponto de vista de César (2013), o termo educativo está relacionado ao aprendizado derivado das experiências do dia a dia, ou seja, das diferentes situações resultantes da nossa interação com diferentes pessoas nos mais variados locais. Este convívio, nas palavras de César (2013, p. 54), “é educativo, porque é um processo de formação não-planejado pedagogicamente, isto é, os conteúdos/ações pensados, executados e avaliados não são sistematizados". Enquanto que o pedagógico ou educacional, na mesma linha de pensamento, tem a função de: 
[...] promover o desenvolvimento de conteúdos/ações específicas nas diversas áreas de conhecimento, de forma crítica, reflexiva e sistematizada - planejada/organizada a partir da utilização de estratégias e metodologias, visando a atingir/alcançar resultados previstos por um ou vários objetivos. Enfim, enquanto no ato educativo, os conteúdos/ações (fatos pedagógicos) são espontâneos, assistematizados, sem metodologia; no ato pedagógico ou educacional, os conteúdos/ações são previamente pensados e planejados (CÉSAR, 2013, p. 54).

Sem estendermos ainda mais a discussão conceitual abordada acima, entendemos que:

Robótica "Pedagógica" ou "Educacional" refere-se ao conjunto de processos e
procedimentos envolvidos em propostas de ensino e de aprendizagem que utilizam os
dispositivos robóticos como tecnologia de mediação para a construção do
conhecimento. Dessa forma, as discussões sobre Robótica Pedagógica não se
restringem às tecnologias ou aos artefatos robóticos e cognitivos em si, nem ao
ambiente físico, onde as atividades são desenvolvidas, e sim às possibilidades
metodológicas de uso e de reflexão das/sobre tecnologias informáticas e robóticas nos
processos de ensino e de aprendizagem (CÉSAR, 2013, p. 55).

Com base no exposto, de maneira específica, adotaremos nesta revisão o termo Robótica Educacional (RE) a partir das ideias de César (2013), ao entendê-la como um conjunto de procedimentos que, por intermédio de dispositivos robóticos, contribuem para a construção do conhecimento. Com isso em mente, e tendo por base os conceitos multidisciplinares que a RE oferece ao levarmos em conta a construção de modelos que levam "o educando a uma gama enorme de experiências de aprendizagem”, como afirma Zilli (2004, p. 39), consideram-se relevantes as questões elencadas acima, a ponto de vislumbrarmos a necessidade de compreendermos: quais os principais avanços relacionados a robótica educacional e como esta vem sendo utilizada no contexto escolar ao longo dos últimos cinco anos?

Uma vez apresentada a questão norteadora, como objetivo vislumbra-se encontrar, além dos avanços em tal temática, a maneira como a RE vem sendo utilizada no contexto educacional. Destarte, o presente artigo trás, além desta introdução que expõe uma contextualização do tema central da investigação, uma segunda parte abordando brevemente a robótica educacional, seguida de uma terceira seção com a exposição dos procedimentos metodológicos utilizados nesta revisão, além de uma quarta para a exposição dos resultados encontrados e por fim, uma quinta parte para a apresentação das considerações finais. 


\title{
2 A ROBÓTICA EDUCACIONAL: Reflexões iniciais ${ }^{1}$
}

Muitos setores da sociedade têm sido beneficiados com os consideráveis avanços proporcionados pela tecnologia, com a educação não seria diferente. Estudiosos apontam a necessidade de compreensões mais aprofundadas acerca de como a junção entre as tecnologias digitais e o ensino deve ocorrer, com o intuito de se abarcar tanto a parte cognitiva da aprendizagem quanto as habilidades socioemocionais. Nesta conjuntura, o investimento em procedimentos que visam à utilização de tecnologias digitais no processo educativo tem sido uma constante (FUZA et al., 2020).

O período compreendido entre os anos de 1946 e 1953 apresentam os primeiros registros voltados para o campo que viria a ser a robótica educacional, pois nesse período, uma série de conferências foram realizadas pela Fundação Josiah Macy, com o intuito de aproximar, de maneira diversificada e interdisciplinar, acadêmicos e pesquisadores para se estabelecer o que viria a nortear a ciência cibernética. As conferências de Macy, como ficaram conhecidas, constituíram um marco para o campo, pois foram as primeiras a lidar com novos termos e informações necessárias às, hoje conhecidas, tecnologias digitais (MASARO, 2010).

Entretanto, foi em 1964 que Seymour Papert, ao ter acesso ao Laboratório de Inteligência Artificial do Instituto de Tecnologia de Massachusetts (MIT), desenvolveu atividades intelectuais relevantes para a robótica educacional. "Inspirado nas tartarugas de William Grey Walter", evidencia Barbosa et al. (2018, p. 332), Papert “construiu um robô em forma de tartaruga e desenvolveu a linguagem LOGO para controlá-lo", afirma Curcio (2008, p. 17), inserindo assim a robótica no contexto escolar no final da década de 60 .

\begin{abstract}
O esboço desta nova disciplina surgira gradualmente, e o problema de situá-la no contexto da Escola e no ambiente de aprendizagem será melhor apresentado quando a tivermos na nossa frente. Apresento aqui uma nova definição preliminar da disciplina, porém apenas como uma semente para discussão, como aquele grão de conhecimento necessário para que uma criança invente (e evidentemente, construa). Se este grão constituísse a disciplina inteira um nome adequado seria "engenharia de controle" ou até mesmo "robótica" (PAPERT, 1994, p.160).
\end{abstract}

Dentre muitos, um aspecto que merece destaque nas ideias de Papert apresentadas na linguagem de programação LOGO, se deve ao fato de se aceitar o erro como um importante fator de aprendizagem, o que oferece oportunidades para que o aluno entenda por que errou e busque uma nova solução para o problema, "investigando, explorando, descobrindo por si

\footnotetext{
${ }^{1}$ Parte dessas reflexões foram aceitas para publicação nos anais do XIX Seminário Temático Internacional - Seção T1 - Projetos em desenvolvimento sem resultados parciais (PARREIRA; ALVES, 2021). 
próprio, ou seja, a aprendizagem acontece por descoberta" (CURCIO, 2008, p. 25). Em consequência da disposição de Papert em compartilhar seus conhecimentos e saberes, a inserção de computadores nas escolas ganhou força com o passar dos anos, especificamente a partir de “1986 quando a Lego lançou robôs programados usando a linguagem LOGO e, em 1989, quando Seymour Papert se uniu a Lego" (CURCIO, 2008, p. 23). A parceria só aumentou tendo como consequência o lançamento, por parte da empresa, da série LEGO Mindstorms no ano de 1998.

Os kits chegaram ao Brasil via Universidade, tendo como ponto de partida o MIT. Posterior a isso, com a chegada deles nas escolas, e mediante pesquisas de outros, a metodologia foi sendo conhecida e disseminada.

Hoje, os principais projetos de robótica educacional são iniciativas isoladas de universidades, prefeituras ou escolas particulares. A maioria das instituições utiliza kits padronizados, formado por hardware, software e material didático próprios. Algumas, em outra direção, adotam software livre e material reciclado para construção de robôs com diferentes níveis de complexidade (CURCIO, 2008, p. 23).

Para Barbosa et al. (2018), as pesquisas que contribuíram para a disseminação da Robótica Educacional trabalharam tendo como base um referencial comum: Seymour Papert, sendo justo mencioná-lo como um dos precursores no uso da robótica, sempre objetivando incorporar a tecnologia à evolução do pensamento humano. Segundo o próprio Papert (1994), tal perspectiva só é possível frente ao fim da cultura de que ciência e as variadas tecnologias não andam juntas, pois tais pensamentos acabam impedindo o desenvolvimento de um conhecimento científico próprio por parte dos alunos, criando lacunas no processo de ensino aprendizagem que acabam, num futuro próximo, expondo-se como habilidades não atingidas.

Na visão de Lopes (2008), os apontamentos feitos por Papert (1994) atestam que o uso do computador serve mais às questões relacionadas ao processo de ensino-aprendizagem quando possibilitam

[...] a atividade do sujeito, seja a partir de operações lógicas, seja na inter-relação com outras pessoas, $[. .$.$] no que se refere às aplicações do computador na escola, ao invés$ de se conceber o computador a partir da minimização do esforço humano pertinente às rotinas de trabalho, deve-se tomar o computador como instrumento de aprendizagem e, portanto, ser concebido como recurso para pensar e agir sobre, produzindo inovação e conhecimento (LOPES, 2008, p. 38).

É neste contexto que as diferentes tecnologias, dentre elas a RE, tem contribuído com consideráveis inovações no campo educacional, entretanto, ao se enxergar a RE como uma tecnologia aplicável ao contexto de sala de aula, é fundamental que se procure entender todo o 
potencial envolto neste tipo de projeto, ao se dar atenção a abordagem ampla deste em comparação a outros com atuações específicas (LOPES, 2008).

Nesta mesma linha de pensamento, ao se adotar o caminho das variadas tecnologias defendidas por Papert (1994), é fundamental compreender, na visão de Barbosa et al. (2018, p. 334), "que o principal está nas ideias. A tecnologia, o computador, é o meio pelo qual se pode simular, construir uma versão do mundo com a tecnologia, um micromundo de possibilidades de investigação, pesquisa, aprendizagem e ensino".

Destarte, é neste cenário que surge a RE, tendo por referência Seymour Papert e sendo carregada de diferentes entendimentos e interpretações. Lopes (2008, p. 41) por exemplo entende a RE como um "conjunto de recursos que visa o aprendizado científico e tecnológico integrado às demais áreas do conhecimento, utilizando-se de atividades como design, construção e programação de robôs". Para Andrade (2018, p.26), caracteriza-se "como um recurso tecnológico multidisciplinar, envolvendo disciplinas das áreas de engenharia mecânica, engenharia elétrica e inteligência artificial, com viés interdisciplinar", o que nos leva a enxergala como um meio poderoso para se alcançar o desenvolvimento cognitivo dos alunos, sendo possível inclusive, uma nova compreensão relacionada a maneira de se aprender.

Isso posto, corroboramos com o pensamento de Barbosa et al. (2018, p. 334) ao compreendermos a RE como um processo de trabalho em que se aprende "a discutir e a trabalhar em grupo, organizar-se, criar e comunicar, além de fortalecer outras características que nos tornam aptos a conviver e trabalhar em sociedade".

Por fim, tendo sido devidamente expostas nossas reflexões iniciais acerca da RE, apresentaremos na seção a seguir todos os procedimentos metodológicos adotados na construção desta revisão.

\section{DOS PROCEDIMENTOS METODOLÓGICOS}

Para a construção desta pesquisa de revisão bibliográfica, optou-se por uma estratégia voltada para o reconhecimento e uso de bancos de dados virtuais para a coleta de trabalhos similares de duas diferentes fontes, sendo elas: a Biblioteca Digital Brasileira de Teses e Dissertações (BDTD), e o Catálogo de Teses e Dissertações da CAPES (CTD).

Tais bases de dados foram selecionadas por terem um reconhecimento significativo no meio acadêmico. Ambas permitem a consulta de teses e dissertações de diferentes instituições 
ao mesmo tempo, a BDTD possui a vantagem de remeter o pesquisador diretamente ao texto completo da dissertação ou tese, o que não acontece com o CTD, entretanto, este último possui obrigatoriamente em seus bancos de dados, o registro de todas as teses e dissertações dos programas de pós-graduação das Universidades Brasileiras, por ser o sistema oficial do governo vinculado ao Ministério da Educação (MEC) (UNESP, 2013).

Apresentadas as bases de dados que serão utilizadas, remetemo-nos aos procedimentos defendidos por Galvão e Pereira (2014, p. 183) para a elaboração de uma revisão, ao passo que estes preveem, de acordo com os autores, a "elaboração da pergunta de pesquisa, a busca na literatura, a seleção dos manuscritos, a extração dos dados, a avaliação da qualidade metodológica, a síntese dos dados, a avaliação da qualidade das evidências e a redação e publicação dos resultados". Posto isso, demos início a construção desta revisão, evidenciando a seguir a questão norteadora, além das estratégias de busca utilizadas para a seleção das pesquisas.

\subsection{Da Questão Norteadora, da Estratégia de Busca e Seleção dos Manuscritos}

Como etapa fundamental desta revisão, especificou-se uma questão norteadora factível de resposta, com o intuito de que esta auxiliasse a busca de manuscritos relevantes nas bases de dados em prol da sua resolução. Como questão central do estudo, temos: Quais os principais avanços relacionados a robótica educacional e como esta vem sendo utilizada no contexto escolar ao longo dos últimos cinco anos?

Uma vez elaborada a pergunta, estabeleceu-se as palavras-chave que deveriam ser pesquisadas, sendo elas: Robótica Educativa, Robótica Pedagógica e Robótica Educacional. Apesar da opção pelo uso do termo Robótica Educacional, justificada na introdução desta pesquisa, o uso dos três termos na busca não deve ser encarado como equívoco, apenas como uma precaução no intuito de não perder uma boa investigação, ao passo que recordamos das palavras de César (2009, p.25) quando diz, "ainda que não chegue a constituir um equívoco, [...] é facilmente perceptível uma certa confusão em torno da definição" dos termos entre os autores, parecendo não existir uma preocupação ou mesmo consenso nesta questão.

Posto isso, ao realizarmos a busca automática nas bases de dados especificadas anteriormente, a string de busca foi definida da seguinte forma: "ROBÓTICA EDUCATIVA" OR “ROBÓTICA PEDAGÓGICA” OR "ROBÓTICA EDUCACIONAL”. A partir dessas strings, obtivemos os seguintes resultados, que podem sem observados na tabela 1. 
Tabela 1 - Resultado geral das buscas nas bases de dados

\begin{tabular}{ccc}
\hline Bases de dados & End. eletrônico & $\begin{array}{c}\text { Quantidade de } \\
\text { manuscritos }\end{array}$ \\
\hline $\begin{array}{c}\text { Biblioteca Digital Brasileira de } \\
\text { Teses e Dissertações (BDTD). }\end{array}$ & $\underline{\text { https://bdtd.ibict.br/vufind/ }}$ & 111 \\
\hline $\begin{array}{c}\text { Catálogo de Teses e Dissertações } \\
\text { (CTD). }\end{array}$ & $\underline{\text { https://catalogodeteses.capes.gov.br/catalogo- }}$ & 189 \\
\hline TOTAL & teses/\#!/ & 300 \\
\hline
\end{tabular}

Fonte: Os autores (2020).

$\mathrm{Na}$ tabela acima podemos perceber, além das bases de dados utilizadas, seus respectivos endereços eletrônicos e o total de manuscritos localizados, o que perfaz um total de 300 pesquisas, destas, 111 foram localizadas na BDTD, e 189 na CTD.

Realizada a busca geral, prosseguimos com o refinamento da mesma. Em um primeiro momento fizemos uso de alguns critérios específicos de inclusão e exclusão, elaborados com o intuito de selecionar as pesquisas relacionadas a nossa área de interesse, bem como ao intervalo de tempo escolhido. Apenas após este refinamento, seguimos com a investigação. Tais critérios/filtros podem ser observados no quadro 1.

\begin{tabular}{|c|c|}
\hline CRITÉRIOS DE INCLUSÃO & CRITÉRIOS DE EXCLUSÃO \\
\hline Manuscritos publicados entre 2016 e março de 2021. & Manuscritos publicados antes de 2016. \\
\hline $\begin{array}{c}\text { Pesquisas relacionadas a educação, ensino e ensino de ciências e } \\
\text { matemática. }\end{array}$ & Pesquisas fora da área de interesse. \\
\hline $\begin{array}{c}\text { Pesquisas que evidenciem como a robótica está sendo trabalhada } \\
\text { no contexto escolar e contribuam para a resposta das questões } \\
\text { norteadoras. }\end{array}$ & Produções duplicadas nas bases de busca. \\
\hline $\begin{array}{c}\text { Pesquisas que possuam em seus títulos o termo "Robótica } \\
\text { Educativa", "Robótica pedagógica" ou "Robótica Educacional". }\end{array}$ & $\begin{array}{c}\text { Pesquisas que não façam alusão a robótica } \\
\text { educativa, pedagógica ou educacional em } \\
\text { seus títulos. }\end{array}$ \\
\hline
\end{tabular}

Quadro 1 - Critérios/filtros de inclusão e exclusão, para a seleção das pesquisas.

Fonte: Os autores (2020).

Após o refinamento das pesquisas por meio da aplicação dos critérios de inclusão e exclusão apresentados no quadro 1, restaram um total de 53 trabalhos, sendo 18 na BDTD e 35 na CTD. Cabe ressaltar aqui, que por serem bases de busca com mecanismos distintos, não é possível aplicar exatamente os mesmos filtros em ambas as bases, o que pode ocasionar a presença de uma publicação apenas em uma das bases consultadas. Uma distribuição dessas publicações ao longo do período de tempo selecionado pode ser observada no gráfico 1. Percebe- se uma maior concentração destas publicações no ano de 2017 e 2019, considerando é claro, a área de conhecimento pretendida para a revisão. A ausência de publicações no ano de 
2021 acaba sendo justificável, uma vez que nos mecanismos de busca, o período selecionado vai até março de 2021.

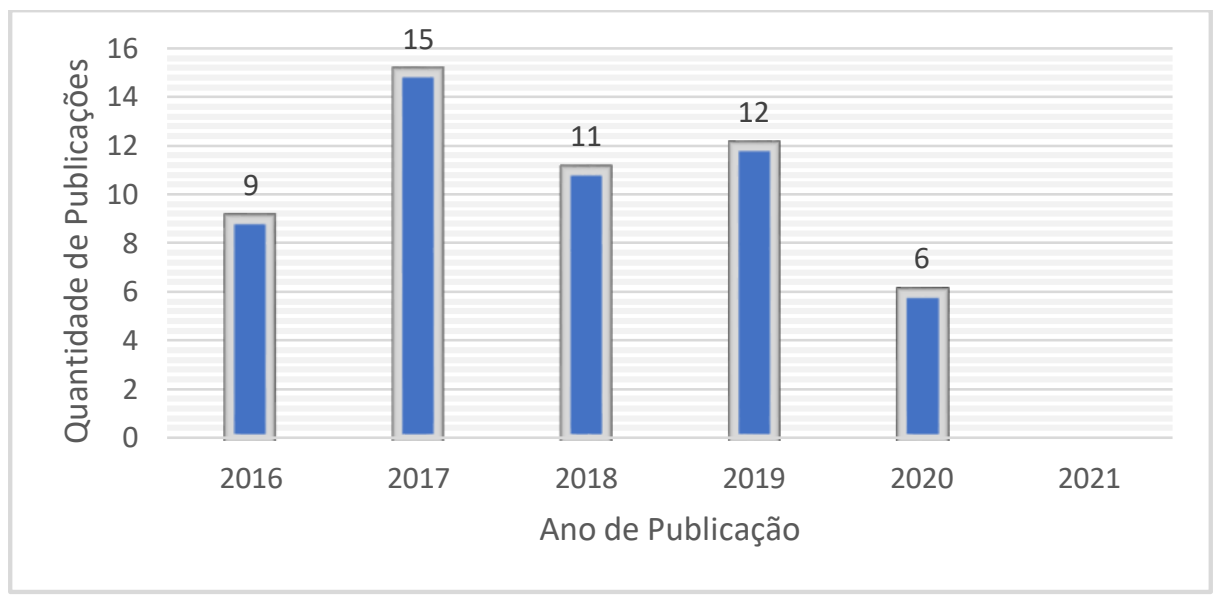

Gráfico 1 - Quantidade de pesquisas e ano de publicação.

Fonte: Os autores (2020).

Seguindo com a organização das teses e dissertações obtidas, e considerando que as ferramentas de procura retornam trabalhos com toda a expressão inserida na string de busca, ou partes dela, prosseguimos com a aplicação dos dois últimos critérios de inclusão, identificando trabalhos que possuíam exatamente os termos "Robótica Educativa", "Robótica Pedagógica" ou "Robótica Educacional" em seus títulos, além daqueles que evidenciavam a maneira como a robótica está sendo trabalhada no contexto escolar e contribuam para a resposta da questão norteadora. Dessa forma, dos 53 trabalhos listados anteriormente, restaram 12 trabalhos, dos quais prosseguimos com a leitura dos resumos. Após a análise destes, foram selecionados 6 manuscritos que irão compor as bases desta revisão bibliográfica. Tais estudos acabaram sendo selecionados por responderem de maneira adequada a questão que norteou esta pesquisa de revisão, abordando de maneira clara os principais avanços da robótica educacional no contexto escolar, além da maneira como a mesma vem sendo utilizada em sala de aula nos últimos anos. As pesquisas selecionadas contendo o autor (referência e ano), o tipo e o título, podem ser observados no quadro 2 .

\begin{tabular}{|c|c|c|}
\hline Autor (referência/ano) & Tipo & Título \\
\hline $\begin{array}{c}\text { Fernando da Costa Barbosa } \\
\text { (BARBOSA, 2016) }\end{array}$ & Tese & $\begin{array}{c}\text { Rede de aprendizagem em robótica: uma perspectiva } \\
\text { educativa de trabalho com jovens }\end{array}$ \\
\hline $\begin{array}{c}\text { Fabiana de Oliveira Andrade } \\
\text { (ANDRADE, 2018) }\end{array}$ & Dissertação & $\begin{array}{c}\text { ROBÓTICA EDUCACIONAL: um estudo da } \\
\text { aprendizagem no Colégio Estadual Secretário Francisco Rosa } \\
\text { Santos (2013-2016) }\end{array}$ \\
\hline
\end{tabular}




\begin{tabular}{|c|c|c|}
\hline $\begin{array}{c}\text { Heitor Felipe da Silva } \\
\text { (SILVA, 2018) }\end{array}$ & Dissertação & $\begin{array}{c}\text { ROBÓTICA EDUCACIONAL COMO RECURSO } \\
\text { PEDAGÓGICO FOMENTADOR DO LETRAMENTO } \\
\text { CIENTÍFICO DE ALUNOS DA REDE PÚBLICA DE } \\
\text { ENSINO NA CIDADE DO RECIFE }\end{array}$ \\
\hline $\begin{array}{c}\text { Robson Souto Brito } \\
\text { (BRITO, 2019) }\end{array}$ & Dissertação & $\begin{array}{c}\text { A PESQUISA BRASILEIRA EM ROBÓTICA } \\
\text { PEDAGÓGICA: um Mapeamento Sistemático com foco na } \\
\text { Educação Básica }\end{array}$ \\
\hline $\begin{array}{c}\text { Fernando Barros da Silva Filho } \\
\text { (SILVA FILHO, 2019) }\end{array}$ & Dissertação & $\begin{array}{c}\text { FUNDAMENTOS DA ROBÓTICA EDUCACIONAL } \\
\text { DESENVOLVIMENTO CONCEPÇÕES TEÓRICAS E } \\
\text { PERSPECTIVAS }\end{array}$ \\
\hline $\begin{array}{c}\text { Ricardo Sousa Santos } \\
\text { (SANTOS, 2020) }\end{array}$ & Dissertação & $\begin{array}{l}\text { O LABORATÓRIO DE ROBÓTICA DA ESCOLA SESI: } \\
\text { um ambiente construcionista de aprendizagem matemática }\end{array}$ \\
\hline \multicolumn{2}{|c|}{$\begin{array}{r}\text { Quadro 2 - Pesquisas selecionadas } \\
\text { Fonte: Os autores (2020). }\end{array}$}
\end{tabular}

A partir disso, e estando formado o corpus da revisão, seguimos com a leitura das pesquisas selecionadas em busca de reflexões que pudessem favorecer o entendimento acerca das compreensões dos estudos relacionados a RE, no intuito de construirmos um panorama adequado, orientados por essas pesquisas.

\subsection{Da Leitura das Pesquisas Selecionadas}

Uma vez selecionadas as pesquisas, que compõem $11 \%$ com relação ao total analisado, e tomando por base os critérios estabelecidos anteriormente, Gil (2002, p. 77) nos ajuda a compreender que a leitura do material deve servir para "identificar as informações e os dados constantes do material impresso, estabelecer relações entre as informações e os dados obtidos com o problema proposto e analisar a consistência das informações e dados apresentados pelos autores”. O autor destaca ainda, que “embora seja desejável certo grau de sistematização do processo de leitura, esta não pode ser prejudicada por normas muito rígidas, sobretudo quando a justificativa das normas não considera adequadamente as diferenças individuais” (GIL, 2002, p. 77).

Com isso em mente, durante a leitura do material selecionado nesta revisão bibliográfica, optamos por uma leitura seletiva pautada nos procedimentos estabelecidos por Yin (2016, p. 74), onde o mesmo sugere que:

Ao ler um estudo pela primeira vez, tente fazer os seguintes registros: O principal tema de estudo, incluindo os problemas/questões que estão sendo abordados. O método de coleta de dados, incluindo a extensão da coleta de dados (p. ex. o número de pessoas entrevistadas, em investigações que usaram entrevistas, ou a duração e amplitude do trabalho de campo em um estudo de observação-participante). Os principais resultados do estudo, incluindo a data específica usada para representar os resultados e as principais conclusões do estudo. 
Segundo este pondo de vista, apresentaremos a seguir os procedimentos para análise, e em seguida a essência, em nossa compreensão, dos trabalhos analisados de forma cronológica.

\subsection{Da Análise das Investigações}

Para o desenvolvimento desta etapa, procuramos utilizar um método de análise que mais se aproximasse do formato de dados obtidos nesta pesquisa, o que acabou nos direcionando para a fundamentação teórico-metodológica de Moraes e Galiazzi (2016), idealizadores da Análise Textual Discursiva (ATD). Como mencionam os autores, a ATD "parte de um conjunto de pressupostos em relação à leitura dos textos examinados [...]. O pesquisador atribui a eles significados a partir dos seus conhecimentos, intensões e teorias", viabilizando assim emergir os significados como objetivos da análise (MORAES; GALIAZZI, 2016, p. 38).

Pautados nos procedimentos envolvidos na ATD, remetemo-nos a Moraes e Galiazzi (2016, p. 43) ao mencionarem que, "na análise exige-se uma leitura cuidadosa, aprofundada e pormenorizada dos materiais do corpus, garantindo-se no mesmo movimento a separação e o isolamento de cada fração significativa". Com isso em mente, seguimos com o movimento de desconstrução dos textos analisados, fragmentando as informações no intuito de entendermos estas como condições necessárias para que, a partir do pesquisador, se possam emergir interpretações capazes de correlacionar os diferentes materiais consultados. Com isso em mente, passamos a considerar e comparar os conceitos defendidos e abordados pelos autores no corpus desta revisão, intencionando a partir destas, a construção das nossas próprias interpretações de maneira indutiva e intuitiva, conforme orientam os autores.

Ao iniciarmos a análise dos textos, passamos a observar as referências utilizadas, o vocabulário empregado pelos autores e as teorias aplicadas, buscamos o estabelecimento de relações entre o material e uma captação do novo, seja por meio de embasamentos teóricos (a priori) ou por meio de conhecimentos subjetivos do pesquisador (emergente), para então, apresentar novas perspectivas.

\subsection{Os Cenários da Robótica Educacional a partir das Produções analisadas}

Barbosa (2016), objetivou em sua pesquisa, compreender qual a perspectiva do desenvolvimento de um trabalho coletivo com robótica educacional com estudantes do ensino 
médio. A realização de atividades no decorrer de alguns anos, oportunizou ao autor acompanhar a trajetória dos estudantes que participaram, inicialmente, de oficinas de robótica em escolas públicas, o que propiciou aos mesmos o acesso a diferentes espaços em escolas particulares, universidades e organizações não governamentais. Segundo o autor, à medida que as atividades avançavam, ficaram mais evidentes o desenvolvimento de autonomia, colaboração, compartilhamento e autoria tecnológica por parte dos sujeitos. A pesquisa teve cunho qualitativo, fez uso de diário de campo, fotografias, filmagens, produção de documentos, questionários e entrevistas. O processo de análise dos dados foi estruturado pelo movimento de aprendizagem em rede com robótica, os diferentes papéis nos acontecimentos de robótica e experiências em engenharia e tecnologia, buscando sempre, nesse processo, compreender qual a trajetória da constituição de uma rede de aprendizagem de robótica educacional que se encontra em expansão e consolidação.

Andrade (2018) aborda em seu estudo uma investigação da aprendizagem, sob a perspectiva dos estudantes, por meio do uso da Robótica Educacional utilizada em um projeto desenvolvido pelo Colégio Estadual Secretário Francisco Rosa Santos (CESEFRS). Tal escolha ocorreu, conforme afirma o autor, devido o notório pioneirismo do projeto, o que tornou a escola referência para as demais unidades de ensino da rede. Neste processo, o pesquisador desenvolveu um estudo de carácter qualitativo e descritivo, utilizando a abordagem de estudo de caso. Como instrumento de coleta de dados, foram utilizados questionários semiestruturados para as entrevistas e a composição de um diário de campo, o que possibilitou ao autor uma análise dos dados com base em uma triangulação entre o objeto, o fenômeno e os sujeitos, de acordo com os dados obtidos. Tal pesquisa permitiu ao autor inferir que os estudantes relacionam a aquisição da aprendizagem, por meio do uso dos recursos, mediante o desenvolvimento dos conceitos das disciplinas que compõem a matriz curricular a partir da interação entre os pares, durante as atividades desenvolvidas.

Em seu estudo, de cunho qualitativo do tipo pesquisa exploratória, Silva (2018) buscou categorizar o Letramento Científico de um grupo de alunos do Ensino Médio de uma Escola de Referência localizada na cidade do Recife. Para isso, o autor procurou verificar como a robótica foi inserida na realidade escolar dos alunos e que ações foram realizadas visando o trabalho com a educação científica e o alcance de um bom Letramento Científico desses estudantes. Acerca dos procedimentos adotados na execução, o pesquisador os caracterizou como pesquisa de observação participante. Como resultados desta investigação, o autor destaca que a Robótica Pedagógica atende aos vários elementos que compõem os objetivos propostos pela educação 
científica, de acordo com os Parâmetros Curriculares Nacionais, o que, consequentemente, influência de maneira direta o Letramento Científico dos alunos envolvidos nas atividades com a robótica. Silva (2018) nos ajuda a compreender ainda em seu estudo, que algumas limitações são impostas às atividades desenvolvidas com a robótica quando fatores relacionados ao seu planejamento, no que diz respeito a interdisciplinaridade, são desconsiderados, o que acaba também comprometendo elementos da cultura científica.

Brito (2019) buscou em sua pesquisa, analisar por meio de um Mapeamento Sistemático de Literatura (MSL) teses e dissertações brasileiras relacionadas a robótica pedagógica na educação básica, contidas na Biblioteca Digital Brasileira de Teses e Dissertações (BDTD) no período de $1^{\circ}$ de janeiro de 2001 a 31 de dezembro de 2017. Para nortear sua pesquisa, o autor buscou identificar as regiões, instituições e áreas que produziram pesquisas de Mestrado e Doutorado em Robótica Pedagógica no Brasil no período de estudo, buscou ainda as características dos kits de robótica utilizados, as teorias que embasavam as pesquisas e as metodologias utilizadas nas investigações durante o período especificado. Com base em suas análises, o autor destaca um crescimento de 52,7\% ao ano nas publicações, aponta uma intensificação no número de trabalhos defendidos no ano de 2013 e uma concentração destes nas regiões Sul, Sudeste e Nordeste do país. Como evidencia ainda o autor, não foram identificadas pesquisas em Robótica Pedagógica na região Centro-Oeste, o que mostra a necessidade de se intensificar as pesquisas nessa região, além de se dar um direcionamento maior para a Educação Infantil e Ensino Médio, na visão de Brito (2019).

Silva Filho (2019) expõe em sua pesquisa as diversas mudanças que a educação vem sofrendo ao longo dos últimos anos, atribui tais mudanças principalmente as tecnologias que advém da informática, o que tem evidenciado no contexto escolar, tanto de escolas públicas como privadas como afirma o autor, o desenvolvimento de atividades que abordam temáticas tecnológicas, dentre elas a Robótica Educacional. Em sua investigação, Silva Filho (2019) traz à tona um movimento científico de apoio e incentivo às atividades de Robótica Educacional dentro da rede pública de ensino do estado do Ceará, tais atividades já ocorrem há alguns anos e tem sido realizadas por professores que não tiveram formação específica nesta temática e mesmo assim, tem contribuído com trabalhos de relevante valor pedagógico. Tais práticas instigaram o pesquisador a questionar quais são os conceitos trabalhados por esses docentes nas atividades de Robótica Educacional, bem como identificar as bases teóricas que norteiam essas ações. Desta forma intencionado, o pesquisador realizou um levantamento de informações na base de dados da Secretaria da Educação do Estado do Ceará dos últimos 10 anos. 
Por meio desta, pode-se identificar os incentivos dados ao desenvolvimento destes projetos, as formações dos professores envolvidos e as instituições que mais evidenciaram a temática abordada. Como resultados desta investigação, o autor aponta que a Robótica Educacional tem se colocado dentro das redes de ensino, oportunizando o trabalho com duas demandas formativas do século, sendo elas: o trabalho colaborativo e o incentivo a resolução de problemas complexos. O pesquisador aponta ainda que a inexistência de um planejamento pautado nos materiais didáticos disponíveis, podem desvirtuar a proposta da Robótica como instrumento de apoio pedagógico.

Em seus estudos, Santos (2020) atribui as constantes transformações da sociedade à evolução tecnológica digital, apontando potencialidades e obstáculos que vão desde a falta de acesso à tecnologia ou mesmo a dificuldades que surgem ao manipulá-la. Ciente dessas adversidades, o autor defende que a inclusão tecnológica, atrelada as habilidades necessárias ao seu uso, devem passar pela Escola. Pautado no construcionismo de Seymour Papert, que defende a utilização de recursos tecnológicos digitais como instrumentos capazes de potencializar a aprendizagem, e sendo ainda este considerado o idealizador do que se conhece hoje como Robótica Educacional (RE), Santos (2020) desenvolveu sua pesquisa, no intuito de identificar quais as proximidades da RE praticada na Escola SESI de Araguaína com o construcionismo de Papert.

Por meio de uma abordagem de cunho qualitativo, e adotando como método de pesquisa o Estudo de Caso, o autor define como suas unidades de análise: O Ambiente Construcionista de Aprendizagem - ACA; A interação Professor-Estudante-Objetos de Aprendizagem construída no ACA, e; A Afetividade suscitada no ACA. Nesta perspectiva, na visão de Santos (2020), identificou-se como padrões teóricos: A formulação de micromundos de aprendizagem matemática; Professor orientador autônomo e Estudante protagonista, e; Aprendizagem Afetiva; que foram combinados aos padrões evidenciados nos dados. Como resultados, o autor aponta uma proximidade entre teoria e prática, ao constatar a construção de conhecimentos científicos-tecnológicos-matemáticos com o desenvolvimento das atividades que compreendem a construção e programação de robôs. Por fim, Santos (2020) compreende que as atividades de RE possuem pontos de intersecção com o construcionismo de Papert, e que nestes pontos a aprendizagem acontece tendo o estudante como protagonista. 


\section{RESULTADOS E DISCUSSÕES}

Não é de hoje que as interações entre alunos ou mesmo entre professor e aluno dentro do contexto de sala de aula são tidas como importantes, tais relações se estabelecem no processo de ensino-aprendizagem, e este processo acaba vinculando um conjunto de ações pedagógicas, que de maneira direta ou indireta, influenciam no desenvolvimento do aluno. Neste viés, o educador ao adotar uma postura dinâmica e interativa, inclina-se a considerar aspectos individuais dos alunos envolvidos no processo de ensino-aprendizagem, habilitando assim a construção e reconstrução de conceitos (NASCIMENTO et al., 2012).

Nessa acepção, acredita-se que a robótica educacional possa contribuir significativamente, uma vez que a própria Base Nacional Comum Curricular (BNCC) nos ajuda a compreender que os "jovens estão dinamicamente inseridos na cultura digital, não somente como consumidores, mas se engajando cada vez mais como protagonistas, [...] sendo necessário reconhecer as potencialidades das tecnologias para a realização de uma série de atividades" (BRASIL, 2018, p. 474).

Embasados nessas considerações, remetemo-nos às pesquisas de Barbosa (2016), Andrade (2018), Silva (2018), Brito (2019) e Silva Filho (2019), ao percebermos uma concordância no sentido de posicionar a robótica como área interdisciplinar, capaz de fomentar as transformações necessárias na rotina de aprendizagem dos alunos por meio da própria tecnologia, além do estímulo a busca por soluções de problemas compostos por conceitos de diferentes disciplinas. Sublinha-se aí a conciliação de benefícios que visam a evolução cognitiva e social dos alunos, acarretando na construção e reconstrução de conceitos nos mais diversos componentes curriculares. O próprio estímulo ao trabalho coletivo dado pela temática acaba fortificando as interações sociais, indo de encontro com as ideias apresentadas na investigação de Nascimento et al. (2012).

Ao prosseguirmos com a análise das produções em busca das respostas às questões norteadoras, podemos perceber, de acordo com nosso entendimento, que os principais avanços relacionados a temática estão voltados para as investigações pautadas em uma robótica mais acessível, que foge da ideia dos kits comerciais, isso tem gerado uma expansão que consequentemente tem favorecido a sua disseminação em instituições públicas e particulares. Apesar de abordagens distintas, nota-se que as investigações observadas sempre mencionam essa temática como estratégia, ferramenta, ou mesmo algo a ser inserido entre diferentes componentes curriculares, sempre visando o aprimoramento no processo de ensino 
aprendizagem, potencializando o trabalho coletivo, permitindo que os estudantes programem, discutam e consequentemente, aprendam brincando. Não conseguimos identificar em nossa revisão, uma investigação específica relacionada a RE enquanto componente curricular, o que nos permite enxergar aqui um espaço que pode gerar investigações futuras. Entretanto, é importante destacarmos que a defesa desta, seja enquanto disciplina, de forma extracurricular ou mesmo opcional, é uma constante nos trabalhos analisados.

Acaba sendo também um consenso entre os pesquisadores analisados, que "as tecnologias digitais nas atividades de robótica estabelecem relações de interação dos sujeitos envolvidos nas atividades" como afirma Barbosa (2016, p.134), objetivando, nas palavras de Brito (2019, p. 83), “dinamizar a aprendizagem através de um ensino baseado na interação mútua entre estudantes e entre estes e professores". Silva (2018, p.113) chama a atenção ainda para a necessidade de interação não apenas entre os sujeitos envolvidos nas atividades de RE, mas também na necessidade de uma "real interação interdisciplinar nos planejamentos de aula" das disciplinas que farão uso deste recurso educacional. Corroborando com esta ideia, Andrade (2018, p. 83) evidencia ainda a necessidade de uma proposta pedagógica interdisciplinar, mantenedora de ações/projetos desenvolvidos com a RE integrada às disciplinas, uma vez que, existem "melhorias no desenvolvimento da aprendizagem nas áreas que possuem interação" com a Robótica Educacional.

\section{CONCLUSÃO}

Neste trabalho de revisão bibliográfica, apresentamos os resultados relacionados aos avanços, bem como a maneira como vem sendo utilizada a robótica no contexto educacional, observando teses e dissertações publicadas nos últimos cinco anos, armazenadas nas duas principais bases de dados virtuais, BDTD e CTD. A partir da análise inicial de seis (6) manuscritos, pudemos perceber, além do mencionado acima, lacunas para futuras investigações.

Apesar de todos os benefícios destacados pelas publicações, não conseguimos perceber um número vultuoso de publicações acadêmicas dentro da nossa área de interesse. Dentre o período analisado, se destacam os anos de 2017 e 2019, com 15 e 12 publicações respectivamente, o que nos leva a crer que a temática em questão ainda carece de atenção, uma 
vez que ainda oferece campo para promissoras investigações futuras, tanto encarando a temática como ferramenta no processo de ensino, ou mesmo como componente curricular.

Assim como Brito (2019), constatamos que grande parte das pesquisas relacionadas a RE se concentram nas regiões Sul, Sudeste e Nordeste, entretanto, as pesquisas nessa área tem aumentado de maneira gradativa em todo o país, o que na visão de Barbosa et al. (2018, p. 348), "amplia e enriquece a produção científica, favorecendo todos os pesquisadores que estão iniciando ou já fazendo pesquisa há algum tempo, pois acelera as investigações em múltiplas direções e com diferentes recursos".

Tecidas tais constatações, como mencionado anteriormente, não identificamos em nossa revisão uma investigação específica relacionada a RE enquanto componente curricular, apesar da menção de Santos (2020) com relação ao desejo demonstrado pela Escola em que realizou sua pesquisa em, futuramente, inserir a RE em sua grade de disciplinas obrigatórias. Tal situação nos permite enxergar um espaço capaz de gerar investigações futuras.

\section{BIBLIOGRAFIA}

ANDRADE, Fabiana de Oliveira. ROBÓTICA EDUCACIONAL: um estudo da aprendizagem no Colégio Estadual secretário Francisco Rosa Santos (2013-2016). 2018. 114 f. Dissertação (Mestrado) - Curso de Educação, Universidade Tiradentes - Unit, Aracaju, 2018. Disponível em:

https://openrit.grupotiradentes.com/xmlui/bitstream/handle/set/3352/Fabiana\%20Oliveira\%20 Andrade_PEP. Acesso em: 10 jul. 2021.

BARBOSA, Fernando da Costa et al. Mapeamento das pesquisas sobre Robótica Educacional no Ensino Fundamental. Texto Livre: Linguagem e Tecnologia, Belo Horizonte, v. 11, n. 3, p. 331-352, 26 dez. 2018. Universidade Federal de Minas Gerais - Pro-Reitoria de Pesquisa. http://dx.doi.org/10.17851/1983-3652.11.3.331-352. Disponível em: http://www.periodicos.letras.ufmg.br/index.php/textolivre/article/view/14347. Acesso em: 7 mar. 2020.

BARBOSA, Fernando da Costa. REDE DE APRENDIZAGEM EM ROBÓTICA: uma perspectiva educativa de trabalho com jovens. 2016. $366 \mathrm{f}$. Tese (Doutorado) - Curso de Educação, Universidade Federal de Uberlândia - Ufu, Uberlândia, 2016. Disponível em: https://repositorio.ufu.br/bitstream/123456789/17564/1/RedeAprendizagemRobotica.pdf. Acesso em: 10 jun. 2021.

BRASIL. Ministério da Educação. Base Nacional Comum Curricular. Brasília, DF, 2018. Disponível em:

http://basenacionalcomum.mec.gov.br/images/BNCC EI EF 110518 versaofinal site.pdf. Acesso em: 20 jul. 2021. 
BRITO, Robson Souto. A PESQUISA BRASILEIRA EM ROBÓTICA PEDAGÓGICA: um mapeamento sistemático com foco na educação básica. 2019. 103 f. Dissertação (Mestrado) - Curso de Educação, Centro de Educação, Universidade Federal de Pernambuco, Recife, 2019. Disponível em: https://repositorio.ufpe.br/handle/123456789/34195. Acesso em: 10 jul. 2021.

CÉSAR, Danilo Rodrigues. POTENCIALIDADES E LIMITES DA ROBÓTICA PEDAGÓGICA LIVRE NO PROCESSO DE (RE)CONSTRUÇÃO DE CONCEITOS CI. 2009. 135 f. Dissertação (Mestrado) - Curso de Educação, Universidade Federal da Bahia, Salvador, 2009. Disponível em: https://repositorio.ufba.br/ri/handle/ri/16044. Acesso em: 5 jun. 2021.

CÉSAR, Danilo Rodrigues. ROBÓTICA PEDAGÓGICA LIVRE: UMA ALTERNATIVA METODOLÓGICA PARA A EMANCIPAÇÃO SOCIODIGITAL E A DEMOCRAT. 2013. 220 f. Tese (Doutorado) - Curso de Educação, Universidade Federal da Bahia, Salvador, 2013. Disponível em: https://repositorio.ufba.br/ri/handle/ri/16087. Acesso em: 5 jul. 2021.

CURCIO, Christina Paula de Camargo. PROPOSTA DE MÉTODO DE ROBÓTICA EDUCACIONAL DE BAIXO CUSTO. 2008. $101 \mathrm{f}$. Dissertação (Mestrado) - Curso de Engenharia, Programa de Pós-Graduação em Desenvolvimento de Tecnologia (Prodetec), Instituto de Tecnologia Para O Desenvolvimento (Lactec), Curitiba, 2008. Disponível em: http://sistemas.institutoslactec.org.br/mestrado/dissertacoes/arquivos/christinacurcio.pdf.

Acesso em: 5 set. 2019.

FUZA, Ângela Francine et al. Tecnologias digitais, letramentos e gêneros discursivos nas diferentes áreas da BNCC: reflexos nos anos finais do ensino fundamental e na formação de professores. Revista Brasileira de Educação, Rio de Janeiro, v. 25, p. 1-26, 2020.

FapUNIFESP (SciELO). http://dx.doi.org/10.1590/s1413-24782019250009. Disponível em: https://www.scielo.br/scielo.php?script=sci arttext\&pid=S1413-24782020000100207. Acesso em: 5 set. 2020.

GALVÃO, Taís Freire; PEREIRA, Mauricio Gomes. Revisões sistemáticas da literatura: passos para sua elaboração. Epidemiologia e Serviços de Saúde, Brasília, v. 23, n. 1, p. 183 184, mar. 2014. FapUNIFESP (SciELO). http://dx.doi.org/10.5123/s1679-

49742014000100018. Disponível em: http://scielo.iec.gov.br/pdf/ess/v23n1/v23n1a18.pdf. Acesso em: 12 jul. 2021.

GIL, Antônio Carlos. Como Elaborar Projetos de Pesquisa. 4. ed. São Paulo: Atlas, 2002. $175 \mathrm{p}$.

LOPES, D. de Q. Exploração de modelos e o nível de abstração nas construções criativas com Robótica Educacional. 2008. 174 f. Tese (Doutorado em Informática na Educação) Curso de Pós-Graduação em Informática Na Educação, Universidade Federal do Rio Grande do Sul, Porto Alegre, 2008.

MASSARO, Leonardo. Cibernética: ciência e técnica. 2010. 213 f. Dissertação (Mestrado) Curso de Sociologia, Instituto de Filosofia e Ciências Humanas, Universidade Estadual de 
Campinas, Campinas, 2010. Disponível em:

http://repositorio.unicamp.br/handle/REPOSIP/278736. Acesso em: 25 ago. 2020.

MORAES, Roque; GALIAZZI, Maria do Carmo. Análise Textual Discursiva. 3. ed. Ijuí: Unijuí, 2016.

NASCIMENTO, Juciene Moura de et al. O papel das interações sociais e de atividades propostas para o ensino-aprendizagem de conceitos quí. Ciência \& Educação, Bauru, v. 18, n. 3, p. 575-592, 2012. FapUNIFESP (SciELO). http://dx.doi.org/10.1590/s151673132012000300006 .

PAPERT, Seymour. A máquina das crianças: repensando a escola na era da informática. Porto Alegre: Artes Médicas, 1994. 211 p. Tradução de: Sandra Costa.

PARREIRA, Ulisses Queiroz; ALVES, Deive Barbosa. A APRENDIZAGEM INVENTIVA COMO RESULTADO DA CONSTITUIÇÃO DA DISCIPLINA DE ROBÓTICA

EDUCACIONAL. XIX Seminário Temático Internacional, Osasco, v. 1, n. 1, p. 1-13, maio 2021. Disponível em: http://anais.ghemat-brasil.com.br/index.php/STI/article/view/48.

Acesso em: 05 ago. 2021.

SANTOS, Ricardo Sousa. O LABORATÓRIO DE ROBÓTICA DA ESCOLA SESI: um ambiente construcionista de aprendizagem matemática. 2020. 118 f. Dissertação (Mestrado) Curso de Ciências e Matemática, Universidade Federal do Tocantins, Araguaína, 2020.

SILVA FILHO, Fernando Barros da. FUNDAMENTOS DA ROBÓTICA EDUCACIONAL DESENVOLVIMENTO, CONCEPÇÕES TEÓRICAS E PERSPECTIVAS. 2019. 175 f. Dissertação (Mestrado) - Curso de Educação, Centro de Humanidades, Universidade Federal do Ceará, Fortaleza, 2019. Disponível em: http://www.repositorio.ufc.br/bitstream/riufc/40480/1/2019 dis fbsfilho.pdf. Acesso em: 5 jul. 2021.

\section{SILVA, Heitor Felipe da. ROBÓTICA EDUCACIONAL COMO RECURSO} PEDAGÓGICO FOMENTADOR DO LETRAMENTO CIENTÍFICO DE ALUNOS DA REDE P. 2018. 127 f. Dissertação (Mestrado) - Curso de Educação Matemática e Tecnológica, Centro de Educação, Universidade Federal de Pernambuco, Recife, 2018. Disponível em: https://repositorio.ufpe.br/handle/123456789/32680. Acesso em: 5 jul. 2021.

UNESP. Qual a diferença entre o Portal de Teses da Capes e as BDTDs do IBICT? 2013. Disponível em: https://www.sorocaba.unesp.br/\#!/biblioteca/diferenca-entre-bdtd-e-capes/. Acesso em: 10 jul. 2021.

YIN, Robert K.. Pesquisa qualitativa do início ao fim. Porto Alegre: Penso, 2016. 286 p. (EPUB). Tradução de: Daniel Bueno; revisão técnica: Dirceu da Silva.

\section{ZILLI, Silvana do Rocio. A ROBÓTICA EDUCACIONAL NO ENSINO}

FUNDAMENTAL: PERSPECTIVAS E PRÁTICA. 2004. 89 f. Dissertação (Mestrado) Curso de Programa de Pós-Graduação em Engenharia de Produção, Centro Tecnológico, Universidade Federal de Santa Catarina, Florianópolis, 2004. Disponível em: http://repositorio.ufsc.br/xmlui/handle/123456789/86930. Acesso em: 5 set. 2020. 


\title{
APÊNDICE 1
}

\author{
AGRADECIMENTOS \\ "Não se aplica". \\ FINANCIAMENTO \\ "Não se aplica".
}

\section{CONTRIBUIÇÕES DE AUTORIA}

Resumo/Abstract/Resumen: Ulisses Queiroz Parreira, Deive Barbosa Alves e Marcos Antonio de Sousa.

Introdução: Ulisses Queiroz Parreira, Deive Barbosa Alves e Marcos Antonio de Sousa.

Referencial teórico: Ulisses Queiroz Parreira, Deive Barbosa Alves e Marcos Antonio de Sousa.

Análise de dados: Ulisses Queiroz Parreira, Deive Barbosa Alves e Marcos Antonio de Sousa.

Discussão dos resultados: Ulisses Queiroz Parreira, Deive Barbosa Alves e Marcos Antonio de Sousa.

Conclusão e considerações finais: Ulisses Queiroz Parreira, Deive Barbosa Alves e Marcos Antonio de Sousa.

Referências: Ulisses Queiroz Parreira, Deive Barbosa Alves e Marcos Antonio de Sousa.

Revisão do manuscrito: Ulisses Queiroz Parreira, Deive Barbosa Alves, Marcos Antonio de Sousa e Adriana de Souza Queiroz.

Aprovação da versão final publicada: Ulisses Queiroz Parreira, Deive Barbosa Alves e Marcos Antonio de Sousa.

Obs.: Além destas etapas supracitadas, a Revista REAMEC recomenda a utilização, caso seja necessário, da Taxonomia de Funções de Contribuidor (CRediT). CRediT é uma taxonomia de alto nível, incluindo 14 funções que podem ser usadas para representar as funções normalmente desempenhadas por contribuidores para a produção científica acadêmica. As funções descrevem a contribuição específica de cada contribuidor para a produção acadêmica. São elas: (1) Conceituação; (2) Curadoria de dados; (3) Análise formal; (4) Aquisição de financiamento; (5) Investigação; (6) Metodologia; (7) Administração do projeto; (8) Recursos; (9) Software; (10) Supervisão; (11) Validação; (12) Visualização; (13) Redação - esboço original; (14) Redação - revisão e edição. Para mais informações sobre estas funções, conferir em: https://casrai.org/credit/.

Os papéis dados na taxonomia acima incluem, mas não estão limitados a papéis tradicionais de autoria. Os papéis não têm como objetivo definir o que constitui autoria, mas, em vez disso, capturar todo o trabalho que permite a produção de publicações acadêmicas.

\section{CONFLITOS DE INTERESSE}

Os autores declararam não haver nenhum conflito de interesse de ordem pessoal, comercial, acadêmico, político e financeiro referente a este manuscrito.

\section{DISPONIBILIDADE DE DADOS DE PESQUISA}

O conjunto de dados que dá suporte aos resultados da pesquisa foi publicado no próprio artigo.

\section{CONSENTIMENTO DE USO DE IMAGEM}

"Não se aplica."

\section{APROVAÇÃO DE COMITÊ DE ÉTICA EM PESQUISA \\ "Não se aplica".}

\section{COMO CITAR - ABNT}

PARREIRA, Ulisses Queiroz; ALVES, Deive Barbosa; SOUSA, Marcos Antonio de. ROBÓTICA NA EDUCAÇÃO: Uma Revisão da Literatura. REAMEC - Rede Amazônica de Educação em Ciências e Matemática. Cuiabá, v. 10, n., 1, e22005, janeiro-abril, 2022. http://dx.doi.org/10.26571/reamec.v10i1.12976.

COMO CITAR - APA

PARREIRA, Ulisses Queiroz; ALVES, Deive Barbosa; SOUSA, Marcos Antonio de. (2022). ROBÓTICA NA EDUCAÇÃO: Uma Revisão da Literatura. REAMEC - Rede Amazônica de Educação em Ciências e Matemática, 10(1), e22005. http://dx.doi.org/10.26571/reamec.v10i1.12976. 


\section{LICENÇA DE USO}

Licenciado sob a Licença Creative Commons Attribution-NonCommercial 4.0 International (CC BY-NC 4.0). Esta licença permite compartilhar, copiar, redistribuir o manuscrito em qualquer meio ou formato. Além disso, permite adaptar, remixar, transformar e construir sobre o material, desde que seja atribuído o devido crédito de autoria e publicação inicial neste periódico.

\section{DIREITOS AUTORAIS}

Os direitos autorais são mantidos pelos autores, os quais concedem à Revista REAMEC - Rede Amazônica de Educação em Ciências e Matemática - os direitos exclusivos de primeira publicação. Os autores não serão remunerados pela publicação de trabalhos neste periódico. Os autores têm autorização para assumir contratos adicionais separadamente, para distribuição não exclusiva da versão do trabalho publicada neste periódico (ex.: publicar em repositório institucional, em site pessoal, publicar uma tradução, ou como capítulo de livro), com reconhecimento de autoria e publicação inicial neste periódico. Os editores da Revista têm o direito de proceder a ajustes textuais e de adequação às normas da publicação.

\section{PUBLISHER}

Universidade Federal de Mato Grosso. Programa de Pós-graduação em Educação em Ciências e Matemática (PPGECEM) da Rede Amazônica de Educação em Ciências e Matemática (REAMEC). Publicação no Portal de Periódicos UFMT. As ideias expressadas neste artigo são de responsabilidade de seus autores, não representando, necessariamente, a opinião dos editores ou da referida universidade.

\section{EDITOR}

Rogerio dos Santos Carneiro

\section{HISTÓRICO}

Submetido: 10 de setembro de 2021.

Aprovado: 09 de dezembro de 2021.

Publicado: 14 de janeiro de 2022. 